\title{
Neoplasia intra-epitelial cervical: diagnóstico e tratamento
}

\author{
Cervical intraepithelial neoplasia: diagnosis and treatment
}

Sophie Françoise Mauricette Derchain ${ }^{1}$, Adhemar Longatto Filho², Kari Juhani Syrjanen ${ }^{3}$

\section{RESUMO}

O câncer do colo uterino é hoje doença passível de prevenção secundária. Os métodos de detecção das lesões precursoras e da infecção pelo papilomavírus humano, tais como a citologia oncológica e biologia molecular, são de uso mundialmente difundido. Entretanto, ainda há muita controvérsia em relação à aplicação destes métodos na prática ginecológica. Qual o melhor exame ou a melhor associação de exames que podem ser utilizados, com que intervalo e em quais mulheres permanecem questões que com freqüência geram ansiedade nos consultórios ou nas unidades de saúde. Por outro lado, uma vez detectada a infecção viral ou a neoplasia intra-epitelial cervical, o tratamento dessas mulheres ainda não é consensual e muitos fatores interferem na definição da conduta ótima. O tipo de infecção, gravidade da neoplasia intra-epitelial, tipo histológico encontrado, todos estes aspectos tendem a dificultar o planejamento terapêutico. Esta revisão tem como objetivo abordar, dentro do conhecimento atual e baseado nos consensos vigentes no país, vários aspectos relacionados ao rastreamento das lesões cervicais e as possíveis condutas terapêuticas vigentes.

PALAVRAS-CHAVE: Neoplasia intra-epitelial cervical/diagnóstico; Neoplasia intra-epitelial cervical/terapia; Neoplasia intra-epitelial cervical/prevenção \& controle; Papilomavírus humano

\section{ABSTRACT}

Cervical cancer is nowadays a disease amenable to secondary prevention. Methods for the detection of its precursor lesions and human papillomavirus infection, such as cervical cytology and molecular biology, achieved widespread use worldwide. However, there is still too much controversy regarding the use of these methods in gynecological practice. Which is the best examination or the best association of examinations, and the most adequate time intervals to proceed with screening, are still pending questions, generating anxiety in patients and doctors. On the other hand, the management of women who have been diagnosed with viral infection and/or cervical intraepithelial neoplasia is not yet consensual, and several factors may affect the clinical decision on how to treat them. Therapeutic options are dependent upon the type of viral infection, severity of the cervical intraepithelial neoplasia and its histological type. The aim of the present article was to review the several aspects of cervical cancer screening and its viable treatment.

KEYWORDS: Cervical intraepithelial neoplasia/diagnosis; Cervical intraepithelial neoplasia/therapy; Cervical intraepithelial neoplasia/prevention \& control; Human papillomavirus

\section{Introdução}

No período de 1995 a 1999, estimou-se que o câncer do colo do útero teria no Brasil taxa de incidência de 18,86/100.000 mulheres e mortalidade de 4,31/100.000 mulheres ${ }^{1}$. Diferentemente dos outros cânceres humanos, o câncer cervical é, em princípio, doença evitável, já que apresenta evolução lenta, com longo período desde o desenvolvimento das lesões precursoras ao aparecimento do câncer ${ }^{2}$. A sua prevenção é potencialmente eficaz, pois existem diversas formas de intervenção no combate às múltiplas manifestações da doença ${ }^{3-5}$. Porém, apesar da eficácia dos programas de controle de câncer cérvico-uterino em muitos centros, o carcinoma cervical mantém-se como doença de alta prevalência, incidência e mortalidade. Assim, as estimativas de incidência deste câncer para 2005 permanecem elevadas, com taxas de 22,14/100.000 mulheres ${ }^{6}$. Essa situação não é exclusiva do Brasil e em todo o mundo, a cada ano, meio milhão de mulheres são acometidas por câncer de colo uterino e cerca de metade delas mor-

1 Professora Associada do Departamento de Tocoginecologia da Faculdade de Ciências Médicas da Universidade Estadual de Campinas - UNICAMP - Campinas (SP) - Brasil 2 Pesquisador Científico da Divisão de Patologia do Instituto Adolfo Lutz e Fellow da Universidade do Minho, Escola de Ciências da Saúde, Braga, Portugal 3 Professor, PhD, FIAC, Department of Oncology and Radiotherapy, Turku University Central Hospital, Finland

Correspondência: Sophie Françoise Mauricette Derchain

Rua Dr António Hossri, 629 - Cidade Universitária - 13083-370 - Campinas - SP - Telefone (19) 3788-9305 - e-mail: derchain@fcm.unicamp.br

Recebido em: 6/6/2005 Aceito com modificações em: 29/7/2005 
rem pela doença ${ }^{7}$. Não por acaso, $78 \%$ das novas ocorrências/ano incidem em países em desenvolvimento, evidenciando a convergência entre as condições socioeconômicas subótimas e a precariedade do acesso ao diagnóstico e tratamento das lesões precursoras.

O exame citológico de Papanicolaou ou colpocitologia oncológica é uma das estratégias mais bem sucedidas para a prevenção de câncer, entretanto é necessária infra-estrutura complexa e muito bem organizada para obter resultados satisfatórios: unidades de saúde e profissionais bem treinados para coletar e preparar o material de forma adequada, laboratórios para corar as lâminas e profissionais especializados para lê-las e emitir laudo e, finalmente, médicos treinados para lidar com as anormalidades detectadas ${ }^{8}$. Os testes citológicos envolvem a coleta de células esfoliadas do colo do útero e exame microscópico destas células após coloração. Isto permite detectar células anormais e assim estimar se existe risco de haver lesão precursora não detectável clinicamente e encaminhar essa mulher para investigação complementar se necessário. Embora aparentemente muito simples, esta estrutura não é disponivel em todos os países e apenas poucas regiões têm conseguido reduzir consistentemente suas taxas de prevalência e incidência de câncer do colo por meio de programas organizados de prevenção ${ }^{9}$.

Os programas de controle de câncer do colo uterino continuam baseados na citologia em todo mundo ${ }^{10}$. Entretanto, na maior parte dos países em desenvolvimento, menos de $5 \%$ das mulheres são incluídas nos programas de controle ${ }^{9,11}$. Quando avaliamos a América Latina, observamos que o câncer do colo uterino é a segunda neoplasia mais freqüente e também a segunda causa de morte por câncer em mulheres e os estudos mostram que houve pouca ou nenhuma redução da incidência desde a década de $60^{6,12}$.

Por outro lado, atualmente já está bem definida a relação causal entre o papilomavírus humano (HPV) e o câncer cervical e suas lesões precursoras. Este conhecimento trouxe novas metodologias que podem contribuir para entender a evolução natural da doença e para seu diagnóstico precoce. Na prática clínica, muitas das infeções pelo HPV não são detectadas e regridem espontaneamente sem nenhum prejuízo para a mulher e, embora a infecção pelo HPV seja necessária para o desenvolvimento do câncer cervical, isoladamente não é capaz de induzir a progressão de uma célula normal para célula neoplásica. Mesmo em mulher infectada pelo vírus, o carcinoma cervical é conseqüência relativamente rara e outros fatores são necessários para influenciar esta progressão $\mathrm{O}^{10,13}$. Estabelecer a relação entre a evolução individual da infecção por HPV, neoplasia intra-epitelial cervical (NIC) e câncer invasor é dificil, pois não existem maneiras fidedignas para determinar quais são realmente os indivíduos infectados, quanto tempo dura a infecção e qual a evolução clínica das pessoas infectadas. Apenas cerca de 15 tipos de HPV têm relação com o câncer cervical; por outro lado, como muitas mulheres apresentam infecção transiente, que pode não ser detectada por um único exame ou mesmo por exames realizados em determinados intervalos, os resultados dos estudos de prevalência ou incidência devem ser considerados com cautela. Adicionalmente, ainda não está definida qual a carga viral necessária para causar lesão e, assim, a detecção de HPV por métodos muito sensiveis pode superestimar o número de infecções realmente de risco $^{14}$.

Ainda existem controvérsias quanto aos fatores relacionados às formas de contágio pelo HPV, sua persistência e o aparecimento de lesão histológica. Tem sido demonstrado que o maior número de parceiros sexuais estaria mais relacionado com a infecção pelo vírus, ao passo que o início da atividade sexual precoce, o uso de contraceptivos hormonais orais, a paridade e o tabagismo estariam associados com a persistência viral e progressão para câncer ${ }^{15}$. Assim, embora virtualmente todos os casos de NIC 3 ou câncer cervical contenham HPV de alto risco oncogênico, para que este virus cause alguma lesão vários co-fatores parecem estar envolvidos. Ainda não está clara, entretanto, a relação destes co-fatores com a progressão das lesões ${ }^{14}$. Outro elemento complicador no estudo da relação entre infecção pelo HPV e neoplasia do colo do útero é que não existe consenso em relação ao que é lesão pré-neoplásica verdadeira, se NIC 1, 2 ou 3 ou se apenas NIC 2 ou 3. Embora haja contínuo esforço em identificar padrões que permitam melhor desempenho da citologia ${ }^{16,17}$, estes parâmetros morfológicos, apontados pela avaliação citológica ou histológica, apresentam grande variedade interobservador e mesmo intra-observador, tornando dificil concluir qual a verdadeira proporção de casos que progredirão para câncer em cada grupo de lesões.

Na última década, com o progresso substancial no conhecimento da resposta do hospedeiro à infecção pelo HPV, vacinas altamente imunogênicas com baixas doses de antígenos e capazes de induzir anticorpos neutralizados genótipo-específicos foram desenvolvidas. As vacinas atualmente utilizadas têm como alvo os tipos 16 e 18, causadores da maioria dos carcino- 
mas cervicais, e/ou 6 e 11, responsáveis pela maioria dos condilomas. Até o momento, foram produzidas vacinas para dez tipos de $\operatorname{HPV}(6,11$, $16,18,31,33,35,39,45$ e 58 ), sugerindo que, futuramente, poderão ser utilizadas em vacinas polivalentes ${ }^{18}$. A vacinação é bem tolerada e induz títulos de anticorpos neutralizadores cerca de 50-100 vezes mais elevados que uma infecção natural, sendo que a proteção contra a infecção já está bem definida ${ }^{15}$. O desenvolvimento de vacina profilática efetiva parece possível, porém para sua aplicação populacional vários atributos são necessários: 1) deve ser segura, pois será administrada em individuos jovens, normais, dos quais a grande maioria, mesmo sem serem vacinados, não desenvolverão câncer induzido por HPV; 2) deve ser passivel de ser usada em lugares de recursos escassos. A vacina deve ser acessivel para produção e venda, ser efetiva em dose única e não ser administrada somente por via injetável; 3) a proteção deve ser duradoura, pois não é prático nem desejável revacinar freqüentemente; 4) deve conferir redução substancial na incidência do câncer cervical, utilizando para isto os tipos virais mais encontrados nos carcinomas ${ }^{19}$. Portanto, é provável que, mesmo com programa eficaz de vacinação, por várias décadas ainda será necessário identificar e conduzir adequadamente mulheres com alguma alteração citológica ou colposcópica.

Assim, o objetivo desta revisão é avaliar o conhecimento atual da prevenção do câncer cervical por meio do rastreamento e o tratamento das lesões precursoras do câncer do colo uterino.

\section{Rastreamento do câncer do colo uterino}

Desde 1988 o Ministério da Saúde e o Ministério da Previdência e Assistência Social, em associação com as diversas Sociedades envolvidas com a questão do câncer de colo uterino, vêm realizando seminários e reuniões de consenso sobre a periodicidade e faixa etária no exame de prevenção do câncer cérvico-uterino, nomenclatura e controle de qualidade dos exames citológicos. Estes encontros têm como principal finalidade estabelecer diretrizes para diagnóstico e terapêutica das lesões cervicais. Já é consenso que a coleta da colpocitologia é preconizada em mulheres sexualmente ativas ou com idade igual ou superior a $25 \operatorname{anos}^{20}$, com repetição em um ano caso o resultado seja normal, e a seguir, trienal.

Para otimizar o desempenho da colpocitologia é de fundamental importância a compreensão dos resultados emitidos nos laudos citológicos. A no- menclatura brasileira para laudos citopatológicos cervicais contempla aspectos de atualidade tecnológica e sua similaridade com o Sistema de Bethesda ${ }^{21}$ facilita a equiparação dos resultados nacionais com aqueles encontrados nas publicações científicas internacionais. Foram introduzidos novos conceitos estruturais e morfológicos, o que contribui para o melhor desempenho laboratorial e serve como facilitador da relação entre a citologia e a clínica.

A citologia pode ser coletada de maneira convencional ou em meio líquido. $\mathrm{Na}$ coleta de citologia em meio líquido, células esfoliadas do colo do útero são transferidas para um líquido fixador e processadas em laboratórios. O custo da citologia de meio líquido é significativamente maior que da citologia convencional, mas tem como vantagem maior representatividade de células coletadas transferidas para a lâmina, redução das citologias insatisfatórias, possibilidade de utilizar o material remanescente para realizar testes de biologia molecular e sensibilidade maior para detecção de lesões de alto grau ${ }^{22}$. A nomenclatura brasileira solicita que seja identificado o tipo de amostra, se de meio liquido ou convencional, pois a adequação do material é avaliada de forma diferente para cada método. Quando coletada em meio líquido, é fundamental especificar qual sistema foi usado, devido às variações encontradas em cada sistema relacionadas às soluções utilizadas para conservação do material e a forma de processamento das amostras ${ }^{23}$.

A avaliação pré-analítica consiste em identificar as amostras específicas que devem ser rejeitadas, amostras inadequadamente identificadas, danificadas ou ausentes. Caso a amostra não possa ser considerada adequada para leitura por outros motivos, esta informação deve ser especificada. Amostras inadequadas implicam nova coleta do exame citológico assim que possivel.

Amostras adequadas podem ser classificadas em satisfatórias ou insatisfatórias. Esta insatisfação pode ser justificada por material acelular ou hipocelular ou pela leitura prejudicada devido a sangue, piócitos, artefatos de ressecamento, contaminantes externos, intensa sobreposição celular ou outros especificados. Entre os aspectos a serem considerados na adequação da amostra também é importante verificar a presença de elementos do epitélio escamoso, glandular e metaplásico. Da mesma forma que as amostras inadequadas, as amostras insatisfatórias implicam nova coleta.

Uma vez satisfatória, a amostra será classificada como dentro dos limites da normalidade, considerando-se o material examinado com alte- 
rações celulares benignas ou com atipias celulares. O acréscimo da expressão "no material examinado" visa estabelecer de maneira clara o aspecto do momento do exame. As alterações celulares benignas incluem inflamação, reparação, metaplasia escamosa imatura, atrofia com inflamação, radiação e outras. É importante notar que a metaplasia somente é considerada quando imatura, pois a metaplasia madura já tem sua diferenciação escamosa definida.

As atipias celulares, tanto de células escamosas (ASC) como de células glandulares, merecem especial atenção, pois incluem atipias celulares de significado indeterminado, lesão intra-epitelial de baixo grau, lesão intra-epitelial de alto grau, lesão intra-epitelial de alto grau não podendo excluir micro-invasão, carcinoma epidermóide invasor, adenocarcinoma in situ, adenocarcinoma invasor e outras neoplasias.

Existe forte correlação entre as anormalidades detectadas pelo exame citológico e a detecção do HPV. Embora cerca de 11\% das mulheres com citologia normal apresentem HPV detectável, esta proporção atinge $73 \%$ entre aquelas cujos exames mostram alguma alteração ${ }^{24,25}$. Outro aspecto a ser considerado quando se avalia a utilização dos testes de detecção viral nos programas de rastreamento é a estimativa de risco que uma mulher com citologia normal possa vir a desenvolver ou apresentar NIC ou câncer cervical: estudos transversais têm demonstrado relação proporcional entre a detecção do HPV e a evolução das mulheres com citologia inicialmente normal para lesões de alto grau. Estudos de coorte reconstituída demonstraram que, entre as mulheres com alta carga de HPV 16, o risco de evoluir para NIC 3 é mais elevado quando comparadas com mulheres nas quais o HPV 16 não foi detectado ${ }^{26}$.

$\mathrm{O}$ teste de captura de híbridos II (CH II) para detecção de HPV tem sido indicado como teste adjunto ao exame de Papanicolaou, em alguns paí$\operatorname{ses}^{27,28}$. Deve-se considerar que a infecção pelo HPV é transitória em $80 \%$ dos casos e apenas $20 \%$ das mulheres com um teste de HPV positivo apresentarão NIC. Existe ainda alguma controvérsia em relação à utilização da $\mathrm{CH}$ II em mulheres com mais de 30 anos de idade, época da vida em que a especificidade da $\mathrm{CH}$ II é significativamente melhor, pois nesta faixa etária, a prevalência da infecção pelo HPV de caráter transitório é menor que em mulheres muito jovens ${ }^{29,30}$. Em programas de rastreamento primário em mulheres com 30 anos ou mais, os testes de detecção de HPV têm aumento de 20 a $30 \%$ na sensibilidade com queda de $10 \%$ na especificidade, quando comparados com a citologia, tanto convencionais como de meio líqui- do. A associação da citologia e da biologia molecular pode elevar a sensibilidade e o valor preditivo negativo para cerca de $100 \%$, sugerindo que mulheres com ambos os exames negativos possam ser submetidas a novo rastreamento em intervalos maiores. Entretanto, o custo dos testes de HPV permanece como um impedimento maior para sua aceitação em programas de prevenção de câncer. O cálculo do custo/efetividade vai variar muito de uma população para outra e está relacionado não só ao custo do exame, mas à infra-estrutura disponivel, o intervalo já preconizado entre os exames e o controle de qualidade vigente por cada legislação. E finalmente, embora aparentemente simples, muito pouco se conhece em relação ao impacto psicológico e emocional relacionado ao referir a uma mulher que ela é portadora de uma infecção por HPV, doença sexualmente transmissivel com potencial efeito carcinogênico ${ }^{14}$.

Existem poucas dúvidas de que o teste molecular para identificação do HPV é de grande utilidade para ser utilizado como teste adjunto à citologia, sobretudo nos casos citológicos de atipias de significado indeterminado ou mesmo na rotina de rastreamento de lesões cérvico-vaginais em mulheres com 30 anos ou mais. Entretanto, estudos longitudinais de grandes populações ainda são necessários para se estabelecer com segurança o aumento dos intervalos de rastreio e a construção de protocolos internacionais e nacionais sobre o seguimento de pacientes HPV-positivas e citologia negativa ${ }^{20}$. Recentemente, a organização Mundial de Saúde, por intermédio da IARC (International Agency for Research on Cancer) ${ }^{20}$, ratificou a importância da identificação do HPV de alto risco como opção de triagem populacional em um relatório (press release 151).

As categorias citológicas anormais continuam motivando discussões importantes referentes a sua prevalência e propedêutica recomendada. Para todas as atipias de significado indeterminado, o sistema de nomenclatura brasileiro optou por criar uma categoria separada, e mais ainda, uma categoria de "origem indefinida" destinada àquelas situações em que não se pode estabelecer com clareza a origem da célula atípica. As ASC de significado indeterminado, de acordo com o sistema de Bethesda, incluem as de significado indeterminado e aquelas em que não se pode afastar lesão intra-epitelial de alto grau. Sua proporção varia entre os diversos serviços, sendo responsável por quase dois terços dos resultados citológicos alterados e é significativamente maior quando a amostra é coletada em meio líquido, podendo corresponder a 6 ou $7 \%$ dos esfregaços ${ }^{5,22}$. O diagnóstico é de dificil reprodutividade interobserva- 
dor $^{31}$ e 5 a $17 \%$ das mulheres com estas atipias apresentam NIC 2 ou 3 quando submetidas a avaliação histológica ${ }^{32,33}$. Existem três opções muito discutidas para completar a propedêutica de uma mulher com ASC de significado indeterminado: repetir a citologia, realizar a colposcopia de imediato ou fazer um teste para detecção de HPV de alto risco. Cada opção tem suas vantagens e desvantagens e o sucesso de cada uma depende do número de NIC 2 ou 3 detectados. Na vigência de resultado sugestivo de ASC em que não se pode afastar lesão de alto grau, a colposcopia é recomendada para todas as mulheres, devendo ser realizada sem necessidade de outros exames ${ }^{27}$.

As atipias de células glandulares também podem ser descritas como possivelmente não neoplásicas ou não se pode afastar lesão intraepitelial de alto grau. É diagnóstico incomum, porém mais de $50 \%$ das mulheres apresentam alguma lesão histológica significativa ${ }^{34}$. As lesões mais freqüentes são de origem escamosa, incluem de NIC 2 ou 3 a câncer invasor, porém, proporção significativa de mulheres apresenta lesões histológicas pré-invasoras ou invasoras de origem glandular. O papel da detecção viral é desconhecido nas atipias glandulares, embora haja grande correlação entre o resultado da CH II e a gravidade da lesão cervical ${ }^{35,36}$. De maneira geral, toda mulher com atipias de células glandulares deverá ser imediatamente submetida a colposcopia com biópsia das áreas anormais. Muitas mulheres com colposcopia normal ou insatisfatória serão submetidas a conização diagnóstica e avaliação endometrial caso a alteração citológica se mantenha ${ }^{27}$.

O resultado de lesão intra-epitelial de baixo grau no exame citopatológico não é necessariamente sinônimo de NIC 1 e cerca de 15 a $30 \%$ destas mulheres terão NIC 2 ou NIC 3 na avaliação histológica ${ }^{4,33}$. Por outro lado, muitas mulheres cujo exame citológico apontou lesão intraepitelial de baixo grau têm colposcopia satisfatória e normal. A recomendação de referir toda mulher com citologia sugestiva de lesão intra-epitelial de baixo grau para colposcopia é baseada no fato de que a colposcopia é o método que tem a maior probabilidade de afastar NIC 2 ou 3 histológico. O papel da CH II permanece controverso para alguns em relação à utilização dos testes de detecção viral em mulheres cujo resultado citológico apresenta alterações menos acentuadas. Como podemos observar, a conduta propedêutica para as mulheres que apresentam ASC de significado indeterminado e lesões escamosas de baixo grau é muito semelhante e varia desde a repetição da citologia, testes para detecção do HPV até colposcopia com biópsia. Obviamente, a realização de colposcopia com biópsia eleva os custos do atendimento, além de submeter a mulher à ansiedade e ao desconforto $^{29}$. Embora a maior parte das mulheres com ASC não tenha doença clinicamente significativa, proporção não desprezivel e muito variável apresenta NIC 2 ou 3, de forma que em mulheres regularmente rastreadas por citologia, cerca de $30 \%$ daquelas que vêm a apresentar NIC 2 ou mais tinham antecedente de ASC em esfregaço anterior $^{4,31,32}$. O teste para HPV de alto risco positivo nas mulheres com ASC pode indicar a presença de lesão em parte significativa dos $\operatorname{casos}^{29}$. Por isso, algumas entidades como a Sociedade Americana de Colposcopia e Patologia Cervical recomenda o chamado teste reflexo, que é a realização da $\mathrm{CH}$ II em pacientes com $\mathrm{ASC}^{37}$.

O custo dos procedimentos é elemento muito relevante a ser considerado: se a colposcopia for o método propedêutico adotado em mulheres com ASC de significado indeterminado ou lesões escamosas de baixo grau, não é necessário repetir a citologia ou realizar $\mathrm{CH}$ II para efetuar um diagnóstico correto, mas os gastos do rastreamento podem se elevar substancialmente ${ }^{10}$. Caso se opte por repetir a citologia sem realizar colposcopia, ou utilizar o material restante da citologia coletada em base líquida no qual possa ser testada a presença do HPV, alguns programas podem se beneficiar substituindo a segunda citologia pela $\mathrm{CH}$ II ou associando a CH II à nova citologia ${ }^{38-40}$. Entretanto, nem sempre a $\mathrm{CH}$ II tem desempenho significativamente melhor que nova citologia no diagnóstico de NIC 2 ou 3 em mulheres referidas por ASC ou lesão intra-epitelial de baixo grau ${ }^{33}$. Por outro lado é importante ressaltar que quantidades maiores de vírus, traduzidas em maiores valores de carga viral, não diferenciaram adequadamente lesões histológicas mais graves, permitindo apenas certo aumento na especificidade do exame, ao custo de similar perda na sensibilida$\mathrm{de}^{41}$.

Os critérios utilizados para identificar as alterações citológicas classificadas como lesões intra-epiteliais de alto grau são mais claros e consensuais. Estas lesões são mais raras, correspondem a cerca de 1 a $2 \%$ dos esfregaços ${ }^{10}$ e estão associadas com lesões histológicas em mais de $70 \%$ das vezes, sendo que eventualmente encontra-se um câncer invasor ${ }^{5,39}$. A maioria destas mulheres apresenta $\mathrm{CH}$ II positiva e, obviamente, não existe para esses casos nenhuma justificativa para realização dos testes de detecção do HPV como método auxiliar ao diagnóstico. Todas as mulheres com lesões intra-epiteliais de alto grau devem ser imediatamente referidas para 
colposcopia ${ }^{27}$. A Nomenclatura Brasileira de Citopatologia sugere que diante de esfregaço sugestivo de microinvasão, esta suspeita seja registrada no laudo.

Finalmente, embora muito mais raras, os esfregaços citológicos podem identificar, também, lesões glandulares. A classificação citológica inclui o adenocarcinoma in situ. Embora de resolução mais difícil, a citologia apresenta critérios para o reconhecimento desta entidade. Ao emitir laudo de adenocarcinoma invasor, pode-se ainda sugerir a possivel origem da neoplasia, se cervical, endometrial ou sem outras especificações. A categoria sem outras especificações se refere exclusivamente a adenocarcinomas de origem uterina, sendo que, quando forem identificadas lesões de origem glandular extra-uterina, deve ser colocado no quadro das outras neoplasias malignas, especificando qual o tipo em nota complementar. Embora muito freqüentemente associada a infecção por HPV, na investigação das lesões glandulares a colposcopia e confirmação histológica são decisivas e não está comprovado o papel da biologia molecular ${ }^{35,36}$.

\section{Tratamento das lesões histologicamente confirmadas}

A NIC 1 é considerada lesão precursora do câncer cervical, porém muitas destas lesões regridem espontaneamente ${ }^{42}$. Em estudos com seguimentos longos observa-se que apenas cerca de $11 \%$ das NIC 1 progridem para NIC 2 ou 3 e assim existe um dilema: qualquer terapia pode ser considerada exagerada, com estresse desnecessário e custos adicionais, mas deixar uma NIC 1 sem tratamento pode predispor a mulher a um risco maior de desenvolver câncer invasor ${ }^{43}$. Além disso, existe grande variação interobservador, mesmo entre patologistas experientes ${ }^{44}$.

Muitos médicos optam por realizar seguimento cuidadoso com visitas semestrais incluindo coleta de nova citologia e colposcopia ou CH II anual. Esta conduta, entretanto, pode ser considerada somente quando a citologia apresentar lesão intra-epitelial de baixo grau, a colposcopia inicial for satisfatória e a biópsia confirmar NIC $1^{38}$. Espera-se regressão espontânea das lesões em mais de dois terço das mulheres. Após 24 meses, o índice de regressão diminui e lesões persistentes devem ser tratadas. Infelizmente, não existe ainda um marcador ideal para identificar a mulher de maior risco para progressão. Assim, qual- quer tratamento ablativo como cauterização elétrica, a laser ou por crioterapia, ou mesmo excisional, como excisão da zona de transformação ou conização com alça diatérmica ou com bisturi a frio, é aceitável diante de uma NIC $1 \mathrm{com}$ colposcopia satisfatória. Quando a zona de transformação não é totalmente visivel, os tratamentos ablativos são inaceitáveis e a conização com retirada de toda a lesão é necessária. Em casos de adolescentes, grávidas ou mulheres imunossuprimidas, mesmo em face de uma colposcopia insatisfatória, o seguimento com nova citologia e colposcopia é recomendado ${ }^{4}$.

Nas lesões de alto grau, histologicamente confirmadas, toda a zona de transformação deve ser retirada. O tratamento ablativo não é recomendado, pois não permite uma avaliação histológica, e teria suas indicações restritas a mulheres com colposcopia satisfatória, concordância entre o resultado da citologia e o exame histológico e ausência de extensão glandular. A excisão da zona de transformação é o tratamento de eleição, tanto para tratamento da NIC 2 ou 3 quanto para detecção de microinvasão ou lesões glandulares. A conização pode ser realizada por bisturi a frio ou laser e, mais recentemente e amplamente divulgado, por alça diatérmica. Hoje, muitos estudos confirmam que a conização com alça diatérmica é tão eficaz quanto a conização com bisturi a frio ${ }^{46}$. A colposcopia é fundamental na indicação da conização, sendo que seu resultado interfere inclusive na técnica a ser utilizada. Mulheres com colposcopia satisfatória podem ser submetidas a conização pela técnica mais custo/efetiva de cada serviço. Quando a colposcopia é insatisfatória, a técnica a ser utilizada será muitas vezes relacionada ao resultado da citologia ${ }^{45}$.

Fator importante a ser considerado em relação ao tratamento conservador da NIC 2 ou 3 é a recidiva. Cerca de $10 \%$ das mulheres tratadas por conização apresentarão recidiva histologicamente comprovada. A presença de recidiva ou persistência de doença não está diretamente relacionada com o estado das margens do cone, sendo que mais de $70 \%$ das mulheres com margens comprometidas não apresentam doença residual quando submetidas a histerectomia. Mulheres com cones com margens livres podem apresentar recorrência por doença multifocal, inadequação da avaliação do espécime cirúrgico ou persistência do HPV. A infecção pelo HPV é freqüentemente eliminada após o tratamento da NIC 2 ou 3, sendo que a persistência viral é o principal fator associado à recorrência da doença ${ }^{47}$.

Após o tratamento conservador da NIC 2 ou 3 espera-se que as recidivas ou recorrências ocor- 
ram em cerca de 30 meses. Assim, classicamente, o seguimento pós-conização deve ser realizado por cerca de cinco anos, a cada seis meses, com citologia e colposcopia. Quase todas as mulheres com doença recorrente ou residual apresentam alterações citológicas. Estudos recentes têm mostrado que o teste de detecção do HPV tem alto valor preditivo no seguimento pos-tratamento, pois o HPV atua como marcador de doença residual não detectada. Observa-se que mulheres com alterações citológicas ou persistência do HPV pósconização têm risco maior de apresentar estas recidivas, embora o valor preditivo positivo destes exames seja baixo. Por outro lado, o teste de HPV tem alto valor preditivo negativo, ou seja, quando o HPV não é detectado de seis meses a um ano após uma conização por NIC 2 ou 3, é muito pouco provável que a mulher venha a ter uma recidi$\mathrm{va}^{47}$.

O adenocarcinoma in situ é a única lesão glandular intra-epitelial claramente caracterizada. Essas lesões são bem menos freqüentes que as lesões escamosas e estão associadas com infecção persistente por HPV de alto risco oncogênico. Não existe ainda consenso quanto à utilidade de graduar as lesões glandulares intraepiteliais. O tratamento do adenocarcinoma in situ é sempre excisional e a conização com bisturi a frio é a conduta preconizada para mulheres jovens e com prole ainda não definida. A avaliação das margens do cone é fundamental para preservação do útero. Mulheres com prole definida ou na menopausa podem ser submetidas a histerectomia total como tratamento definitivo.

Concluindo, embora o câncer do colo do útero seja doença teoricamente passivel de prevenção primária, a detecção e o tratamento adequado das lesões precursoras é atualmente a base para o controle da doença. Ainda são necessários esforços para melhorar a sensibilidade, especificidade e valores preditivos positivos e negativos dos testes diagnósticos, assim como para aumentar a conscientização das mulheres em aderirem aos programas de controle.

\section{Referências}

1. Ministério da Saúde. Instituto Nacional do Câncer. Atlas de mortalidade por câncer no Brasil 1979-1999 [texto na Internet]. INCA; 2002 [citado 2005 Mar 10]. Disponivel em: http://www.inca.gov.br/atlas/ docs/Atlas_completo.pdf

2. Saraiya M, Lee NC, Blackman D, Smith MJ, Morrow B, McKenna MT. Observations from the CDC. An assessment of Pap smears and hysterectomies among women in the United States. J Womens Health Gend Based Med. 2002;11(2):103-9.

3. Syrjänen K. Natural history of cervical HPV infections and CIN. In: Syrjänen K, Syrjänen S, editors. Papillomavirus infections in human pathology. New York: Wiley \& Sons; 2000. p. 14266.

4. Santos ALF, Derchain SFM, Sarian LO, Campos EA, Santos MR, Fonsechi-Carvasan GA. Resultados histológicos e detecção do HPV em mulheres com células escamosas atípicas de significado indeterminado e lesão escamosa intra-epitelial de baixo grau na colpocitologia oncológica. Rev Bras Ginecol Obstet. 2004;26(6):457-62.

5. Gontijo RC, Derchain SFM, Montemor EBL, Sarian LOZ, Serra MMP, Zeferino LC, et al. Pap smear, hybrid capture II, and visual inspection in screening for uterine cervical lesions. Cad Saúde Pública. 2005;21(1):141-9.

6. Ministério da Saúde. Secretaria de Atenção à Saúde . Instituto Nacional do Câncer. Coordenação de Prevenção e Vigilância. Estimativas 2005: incidência de câncer no Brasil. Rio de Janeiro: INCA; 2004.

7. Bosch FX. Epidemiology of human papillomavirus infections: new options for cervical cancer prevention. Salud Publica Mex. 2003;45 Suppl 3:S326-39.

8. Miller AB, Nazeer S, Fonn S, Brandup-Lukanow A, Rehman $\mathrm{R}$, Cronje $\mathrm{H}$, et al. Report on consensus conference on cervical cancer screening and management. Int J Cancer. 2000;86(3):440-7

9. Cronjé HS. Screening for cervical cancer in developing countries. Int $\mathrm{J}$ Gynaecol Obstet. 2004;84(2):101-8.

10. Syrjanen K, Naud P, Derchain SF, Roteli-Martins C, Longatto-Filho A, Tatti S, et al. Comparing PAP smear cytology, aided visual inspection, screening colposcopy, cervicography and HPV testing as optional screening tools in Latin America study design and baseline data for the LAMS study. Anticancer Res. In press 2005.

11. Eluf-Neto J, Nascimento CM. Cervical cancer in Latin America. Semin Oncol. 2001;28(2):188-97.

12.Lazcano-Ponce E, Alonso P, Ruiz-Moreno JA, Hernandez-Avila M. Recommendations for cervical cancer screening programs in developing countries. The need for equity and technological development. Salud Publica Mex. 2003;45 Suppl 3:S449-62.

13. Derchain SF, Roteli-Martins CM, Syrjanen KJ, de Abreu HJ, Martinez EZ, Alves VA. Association of oncogenic human papillomavirus DNA with high grade cervical intraepithelial neoplasia: the role of cigarette smoking. Sex Transm Infect. 1999;75(6):406-8. 
14. Wacholder S. Chapter 18: Statistical issues in the design and analysis of studies of human papillomavirus and cervical neoplasia. J Natl Cancer Inst Monogr. 2003;(31):125-30.

15. Galloway DA. Papillomavirus vaccines in clinical trials. Lancet Infec Dis. 2003;3(8):469-75.

16. Dufloth RM, Messias-Silva SM, Andrade LA, di Loreto C, Munhoz DM, Zeferino LC. Nuclear alterations of cells and atypical metaplastic cells in cervical smears are predictive criteria of highgrade cervical intraepithelial neoplasia. Eur J Gynaecol Oncol. 2005;26(2):186-90.

17. Yamamoto LSU, Alves VAF, Maeda MYS, LongattoFilho A, Utagawa ML, Eluf Neto J. A morphological protocol and guide-list on uterine cervix cytology associated to Papillomavirus infection. Rev Inst Med Trop Sao Paulo. 2004;46(4):189-93.

18. Franceschi S, Clifford G, Plummer M. Prospects for primary prevention of cervical cancer in developing countries. Salud Publica Mex. 2003;45 Suppl 3:S4306.

19. Lowy DR, Frazer IH. Chapter 16: Prophylactic human papillomavirus vaccines. J Natl Cancer Inst Monogr. 2003;(31):111-6.

20. International Agency for Research on Cancer (IARC). IARC confirms efficacy of cervix cancer screening for women 25-65 in reducing mortality [homepage on the Internet]. 2004 [cited 2005 Mar 10]. Available from: http://www.iarc.fr/ENG/Press_Releases / pr151a.html.

21. Solomon D, Davey D, Kurman R, Moriarty A, O'Connor D, Prey M, et al The 2001 Bethesda System: terminology for reporting results of cervical cytology. JAMA. 2002;287(16):2114-9.

22. Longatto Filho A, Pereira SM, Di Loreto C, Utagawa ML, Makabe S, Sakamoto Maeda MY, et al. DCS liquid-based system is more effective than conventional smears to diagnosis of cervical lesions: study in high-risk population with biopsybased confirmation. Gynecol Oncol. 2005;97(2):497500.

23. Alves VA, Bibbo M, Schmitt FC, Milanezi F, Longatto Filho A. Comparison of manual and automated methods of liquid-based cytology. A morphologic study. Acta Cytol. 2004;48(2):187-93.

24. Wolf JK, Franco EL, Arbeit JM, Shroyer KR, Wu TC, Runowicz CD, et al. Innovations in understanding the biology of cervical cancer. Cancer. 2003;98(9 Suppl):2064-9.

25. Bratti MC, Rodriguez AC, Schiffman M, Hildesheim A, Morales J, Alfaro M, et al. Description of a sevenyear prospective study of human papillomavirus infection and cervical neoplasia among 10000 women in Guanacaste, Costa Rica. Rev Panam Salud Publica. 2004;15(2):75-89.
26. Ylitalo N, Sorensen P, Josefsson AM, Magnusson PK, Andersen PK, Ponten J, et al. Consistent high viral load of human papillomavirus 16 and risk of cervical carcinoma in situ: a nested case control study. Lancet. 2000;355(9222):2194-8.

27. Apgar BS, Brotzman G. Management of cervical cytologic abnormalities. Am Fam Physician. 2004;70(10):1905-16

28. Meijer CJ, Snijders PJ, van den Brule AJ. Screening for cervical cancer: should we test for infection with high-risk HPV? CMAJ. 2000;163(5):535-8.

29. Arbyn M, Buntinx F, Van Ranst M, Paraskevaidis E, Martin-Hirsch P, Dillner J. Virologic versus cytologic triage of women with equivocal Pap smears: a metaanalysis of the accuracy to detect high-grade intraepithelial neoplasia. J Natl Cancer Inst. 2004;96(4):280-93.

30. Goldie SJ, Kim JJ, Wright TC. Cost-effectiveness of human papillomavirus DNA testing for cervical cancer screening in women aged 30 years or more. Obstet Gynecol. 2004;103(4):619-31.

31. Santos AL, Derchain SF, Martins MR, Sarian LO, Martinez EZ, Syrjanen KJ. Human papillomavirus viral load in predicting high-grade CIN in women with cervical smears showing only atypical squamous cells or low-grade squamous intraepithelial lesion. Sao Paulo Med J. 2003;121(6):238-43.

32. Silva SMM, Sarian LOZ, Derchain SFM, Campos EA, Montemor EBL, Dufloth RM, et al. Detecção do DNAHPV e carga viral associada a colposcopia como fatores preditivos de lesões histológicas em mulheres com atipia de células escamosas: ASC na colpocitologia. DST J Bras Doenças Sex Transm. 2002;14(6):18-21.

33. Santos AL, Derchain SF, Calvert EB, Martins MR, Dufloth RM, Martinez EZ. Performance of cervical cytology with review by different observers and hybrid capture II in the diagnosis of cervical intraepithelial neoplasia grades 2 and 3. Cad Saúde Pública. 2003;19(4):1029-37.

34. Verdiani LA, Derchain SFM, Schweller M, Gontijo RC, Andrade LAA, Zeferino LC. Atipia de células glandulares em esfregaços do colo do útero: avaliação dos métodos propedêuticos. Rev Bras Ginecol Obstet. 2003;25(3):193-200.

35. Derchain SF, Rabelo-Santos SH, Sarian LO, Zeferino LC, de Oliveira Zambeli ER, do Amaral Westin MC, et al. Human papillomavirus DNA detection and histological findings in women referred for atypical glandular cells or adenocarcinoma in situ in their Pap smears. Gynecol Oncol. 2004;95(3):618-23

36. Oliveira ER, Derchain SF, Rabelo-Santos SH, Westin MC, Zeferino LC, Campos EA, et al. Detection of high-risk human papillomavirus (HPV) DNA by Hybrid Capture II in women referred due to atypical 
glandular cells in the primary screening. Diagn Cytopathol. 2004;31(1):19-22.

38 Wright TC Jr, Cox JT, Massad LS, Carlson J, Twiggs LB, Wilkinson EJ, et al. 2001 consensus guidelines for the management of women with cervical intraepithelial neoplasia. Am J Obstet Gynecol. 2003;189(1):295-304.

39. Wright TC Jr, Cox JT, Massad LS, Twiggs LB, Wilkinson EJ; ASCCP-Sponsored Consensus Conference. 2001 Consensus Guidelines for the management of women with cervical cytological abnormalities. JAMA. 2002;287(16):2120-9.

40. Shirata NK, Longatto Filho A, Roteli-Martins C, Espoladore LM, Pittoli JE, Syrjanen K. Applicability of liquid-based cytology to the assessment of DNA content in cervical lesions using static cytometry. Anal Quant Cytol Histol. 2003;25(4):210-4.

41. Sarian LOZ, Santos ALF, Derchain SF, Figueiredo PG, Morais SS. Carga viral do papilomavirus humano na predição da gravidade de lesões cervicais em mulheres com atipias celulares na colpocitologia oncológica. Rev Bras Ginecol Obstet. 2003;25(5):36570 .

42. Nasiell K, Roger V, Nasiell M. Behavior of mild cervical dysplasia during a long-term follow-up. Obstet Gynecol. 1986;67(5):665-9.
43. Singer A. Management and therapeutic options of low-grade SIL. CME J Gynecol Oncol. 2000;5(1):6972 .

44. Parker MF, Zahn CM, Vogel KM, Olsen CH, Miyazawa $\mathrm{K}$, O'Connor DM. Discrepancy in the interpretation of cervical histology by gynecologic pathologists. Obstet Gynecol. 2002;100(2):277-80.

45. Soto-Wright V, Samuelson R, McLellan R. Current management of low-grade squamous intraepithelial lesion, high-grade squamous epithelial lesion, and atypical glandular cells. Clin Obstet Gynecol. 2005;48(1):147-59.

46. Martin-Hirsch PL, Paraskevaidis E, Kitchener H. Surgery for cervical intraepithelial neoplasia. Cochrane Database Syst Rev. 2000;(2):CD001318.

47. Sarian LO, Derchain SF, Andrade LA, Tambascia J, Morais SS, Syrjanen KJ. HPV DNA test and Pap smear in detection of residual and recurrent disease following loop electrosurgical excision procedure of high-grade cervical intraepithelial neoplasia. Gynecol Oncol. 2004;94(1):181-6. 